MISTRAL MISTRAL

Journal of Latin American Women's

Intellectual \& Cultural History

\title{
Caperucita y la abuela-lobo: Los cuentos de hadas queer de Alejandra Pizarnik
}

\author{
Ludmila Soledad Barbero, Universidad de Buenos Aires / CONICET
}

To cite this article: Ludmila Soledad Barbero. 2021. "Caperucita y la abuela-lobo: Los cuentos de hadas queer de Alejandra Pizarnik.” Mistral: Journal of Latin American Women's Intellectual \& Cultural History 1 (2): 49-64, https://doi.org/10.21827/mistral.2.38028

\begin{abstract}
Near the end of her life, the Argentine poet Alejandra Pizarnik (1936-1972) wrote a series of short prose works that explicitly rewrite fairy tales or take up their atmosphere and some of their elements. Such is the case of "Violario" (1971), which rewrites Little Red Riding Hood, with an emphasis on the link between violence and sexuality, and "A tiempo y no" (1968) which highlights the most sinister elements of Snow White. This last story, along with Sleeping Beauty, The Little Mermaid and Hansel and Gretel are also rewritten in prose pieces, poems and in her Diaries. This article analyzes how these rewritings take place - starting with the convergences and divergences with the hypotexts - to illuminate the anomalous and queer image of childhood created by Pizarnik.
\end{abstract}

\section{Keywords}

Queer childhood; Rewriting of fairy tales; Alejandra Pizarnik; Gender technologies; Childhood Technologies

\section{Resumen}

La poeta argentina Alejandra Pizarnik (1936-1972) hacia el final de su vida escribe una serie de prosas breves que recuperan explícitamente cuentos de hadas, o retoman su atmósfera y algunos de sus elementos. Tal es el caso de "Violario" (1971), que reescribe Caperucita roja, con un marcado énfasis en el cruce entre violencia y sexualidad, y "A tiempo y no" (1968) que retoma y subraya los elementos más siniestros de Blancanieves. Este último cuento, junto con La bella durmiente, La sirenita y Hansel y Gretel son recuperados también en otras prosas, poemas y en los Diarios. Indagar el modo en que tienen lugar estas reescrituras, a partir de las convergencias y divergencias con sus hipotextos, iluminará zonas de la infancia anómala y queer que Pizarnik configura.

\section{Palabras clave}

Infancia queer; Reescrituras de cuentos de hadas; Alejandra Pizarnik; Tecnologías del género; Tecnologías de la infancia 


\title{
Caperucita y la abuela-lobo: \\ Los cuentos de hadas queer de Alejandra Pizarnik
}

\author{
Ludmila Soledad Barbero, Universidad de Buenos Aires / CONICET, Argentina
}

Me detendré en las siguientes obras: "Violario" y "La verdad del bosque" (1971), "A tiempo y no" (1968), "Aproximaciones" (1956-1958), "La enamorada" (1956), y en fragmentos de los Diarios de la autora. Los cuentos de hadas han articulado históricamente "tecnologías de la infancia" (Punte 2018), esto es, han operado como dispositivos en la configuración de subjetividades infantes. No se trata, no obstante, de una relación unidireccional: los cuentos producen una imagen de la niñez que tiene incidencias en el proceso de socialización de sus receptores principales, pero también refractan ciertas ideas previas sobre la infancia y la particular construcción de la niñez que tiene lugar en ellos puede modificarse activamente, adoptando un sesgo ideológico diferente, a través de sus reversiones. En este sentido, en las reescrituras mencionadas se contamina la construcción pizarnikiana de infancia de elementos sexuales, escatológicos y mortuorios. Una de las apuestas más contundentes se vincula con la instalación del deseo lésbico en el corazón de un cuento de hadas, que tiene lugar en "Violario" (como también ocurriera en La condesa sangrienta -1965-). Asimismo, la autora se corre de la construcción de lo femenino en polaridades antinómicas (ángel del hogar versus monstruo) que opera en buena medida en los hipotextos para dar lugar a personajes ambivalentes, que condensan elementos que la cultura patriarcal propende a separar (este es el caso de la conjunción abuela-lobo en "Violario", por ejemplo).

\section{La reescritura de Caperucita roja}

Entre los teóricos que abordan los cuentos de hadas, hay consenso en la idea de que Caperucita roja es, quizás con mucho mayor evidencia que otros relatos, una historia fuertemente sexualizada, en especial en la versión de Charles Perrault. Djuna Barnes en El bosque de la noche exclama: "Dios, los niños saben algo que no pueden decir; les gusta ver a Caperucita y al lobo en la cama" $(1936,9)$. Bruno Bettelheim, haciendo referencia al aspecto cromático del cuento, señala que "Rojo es el color que simboliza las emociones violentas, sobre todo las de tipo sexual" $(2013,191)$. Y Zohar Shavit (1983), en su comparación de la versión de Perrault con la de los hermanos Grimm, enfatiza el sesgo erótico de la primera, por sobre el educativo de la segunda. María $\operatorname{Tatar}^{1}$ (1999), imagina que los narradores folcloristas que pusieron a circular las diferentes versiones que anteceden a Caperucita, debieron complacerse con el potencial del relato para las insinuaciones eróticas. Cuando Perrault publicó su colección de cuentos de hadas en 1697, la historia de Caperucita roja ya llevaba bastante tiempo de circulación. Con respecto a la versión de los hermanos Grimm, la colección de cuentos

\footnotetext{
${ }^{1}$ Tatar releva el antepasado folclórico de Caperucita: "La historia de la abuela", una versión editada en Inglaterra en 1885 que, de acuerdo con el folclorista francés Paul Delaure, circuló oralmente al menos un siglo antes. La protagonista de esta historia logra escapar del lobo. Primero llega a la casa de la abuelita e ingiere carne y vino, que resultan ser carne y sangre de la abuela. Entonces hace un strip-tease y se mete en la cama con el lobo, a quien logra engañar y así poder escaparse.
} 
de hadas, que contenía Caperucita roja, apareció por primera vez en 1812, más de cien años después de que Perrault publicase su primera versión.

La característica más notable de Caperucita es su curiosidad. Ella, a diferencia de otros niños pequeños que aparecen en los cuentos de hadas, no teme en absoluto salir al mundo exterior: el deseo la mueve hacia afuera del hogar. Y, de hecho, salir no está prohibido. Para atravesar el bosque hay un camino seguro; el peligro aparece cuando la niña se aparta de él. Un elemento diferencia a Caperucita roja de relatos como Hansel $y$ Gretel, donde los personajes femeninos tenían un gran poder y poseían la capacidad de proteger o poner en peligro a los infantes desvalidos: aquí las mujeres adultas apenas pueden proporcionar consejos que luego no son tenidos en cuenta. Como señala Bettelheim:

Caperucita roja, de forma simbólica, proyecta a la niña hacia los peligros de sus conflictos edípicos durante la pubertad y, luego, la libera de ellos de manera que puede madurar libre de problemas. Los personajes maternos de la madre y la bruja, que eran tan importantes en Hansel y Gretel, son insignificantes en Caperucita, donde ni la madre ni la abuela pueden hacer nada: ni siquiera amenazar o proteger. En cambio, el personaje masculino es mucho más importante y está disociado en dos formas completamente opuestas: el seductor peligroso que, si se cede a sus deseos, se convierte en el destructor de la niña; y el personaje del padre, cazador, fuerte y responsable.

$(2013,190)$

Hay que tener en cuenta este rol pasivo de las mujeres adultas, porque se trastoca totalmente en "Violario", relato en el que el lobo feroz y la abuelita se amalgaman en una anciana seductora lesbiana con tintes pedófilos y cierta cuota de velada necrofilia. Aquí también, como ocurriera en La condesa sangrienta ${ }^{2}$, Pizarnik instala el deseo de una mujer por otra en el corazón de un cuento de hadas.

Ya en 1968 Pizarnik se encontraba trabajando en "La verdad del bosque". En la entrada del 15 de junio, se lee: "Cahier Jaune: pasar a máquina los textos definitivos y trabajar en 'La verdad del bosque' (esto podría ser un hermoso título)" $(2013,786)$. Luego, el 23 de junio: "Corregir, por ahora 'La verdad del bosque' (I y II) y, acaso antes, "Había una vez"" (789). "Violario" es mencionado el mismo año, casi inmediatamente después: “Trabajé algo en 'Violario' (para vengarme, en parte de S.O. ${ }^{3}$, para salvarnos a los dos: Al Dr. P.R. ${ }^{4}$ y a mí. Salvarnos, o mejor, sanarnos" (791). Luego hay una referencia a la rigurosidad del método de corrección de "Violario": "El método riguroso y artificial con que corrijo 'Violario' tiene la ventaja de permitirme un

\footnotetext{
2 Si pensamos en vinculaciones entre La condesa sangrienta y cuentos de hadas, vale la pena considerar las intertextualidades que establece con La reina de las Nieves y Blancanieves (Véase Barbero 2018), y con Barba Azul, donde hay un imaginario cercano al que se despliega en la pieza de Pizarnik. Me refiero concretamente a la vinculación entre erotismo y muerte (el hombre rico que asesina a cada una de sus esposas como la condesa asesina a mujeres hermosas), y a la idea de cuarto prohibido. En Barba Azul hay una habitación vedada, a la que la esposa no debe entrar y que es donde se acumulan los cadáveres de las anteriores. En La condesa sangrienta también el subsuelo es un espacio dedicado al crimen, un espacio específico de Csejte bañado en sangre. La comparación podría seguir, y más si tenemos en cuenta que Gilles de Rais, personaje que fue muchas veces asociado a Báthory (por Bataille por ejemplo) ha sido pensado como una suerte de Barba Azul.

${ }^{3}$ Esta referencia nos lleva a preguntarnos si la loba literata no tendrá algo que ver con Silvina Ocampo, con quien Pizarnik tenía una fascinación romántico-literaria y de quien la separaba una marcada diferencia de edad.

${ }^{4}$ Referencia al Doctor [Enrique] Pichón Rivière, psicoanalista, por ese entonces, de la poeta.
} 
lenguaje punzante y acerado como un cuchillo" (791). El lenguaje de "Violario" es tan punzante y acerado como su temática.

A diferencia de lo que ocurre en los cuentos de hadas que funcionan con una estructura narrativa bastante ordenada, a saber: introducción, nudo y desenlace, en "Violario" toda la sucesión de eventos se resume en el primer párrafo: "De un antiguo parecido mental con caperucita provendría, no lo sé, el hechizo que involuntariamente despierto en las viejas con cara de lobo. Y pienso en una que me quiso violar en un velorio mientras yo miraba las flores en las manos del muerto" (2014b, 33). Hay un aura de irrealidad sobre toda la escena: "De un antiguo parecido mental" (Ídem). Aparecen fuertes referencias literarias en la construcción del personaje de la loba: "la vetusta femme de lettres", "con ese ardor a lo Renée Vivien, con ese brío a lo Nathalie Clifford Barney" (Ídem). No es sólo una vieja con cara de lobo, es una vieja lesbiana con aires de literata, que además lee su parecido mental, e insiste en que la protagonista mire las flores que adornan al muerto, con una "sáfica unción" (Ídem).

De acuerdo con Fiona Mackintosh (2003), "Violario" es un texto sumamente transgresor como reescritura de Caperucita roja porque plantea una ruptura con la imagen de la infancia como espacio de una inocencia incontaminada. La reescritura pone mucho énfasis en aquello que para Susan Brownmiller es el núcleo de Caperucita roja: "Red Riding Hood is a parable of rape" (1976, 310). "Violario" es, como resulta evidente, y como ya señaló Mackintosh, un juego de palabras que combina "Velorio", espacio donde transcurre la escena, con "Violación", la acción que tiene lugar entre los brazos de la anciana que aparentemente solo acompaña a la protagonista en una escena de duelo. Se trata de un abuso invisible para los demás: "Nadie hubiera podido conjeturar, viendo mi estampa adolescente, que la vetusta femme de lettres hacía otra cosa que llorar en mi cuello" (Pizarnik 2014b, 33). El carácter velado de la violencia la vuelve doblemente siniestra. Tenemos, de un modo similar a lo que ocurre en $L a$ condesa sangrienta ${ }^{5}$, a una lesbiana de la que no se sabe abiertamente que lo es, y cuyo abuso permanece, en cierta medida, invisible. El clóset del deseo lesbiano va de la mano de la configuración de la lesbiana como monstruo (aquí vieja-lobo, allí asesina de vírgenes a sangre fría). La co-protagonista de "Violario" es, al mismo tiempo, la doliente abuelita y el lobo feroz. En este sentido, el orden del disfraz que observamos en esta apariencia de anciana piadosa era central en las diferentes versiones de "Caperucita roja", donde el lobo feroz se travestía de abuelita para conseguir que la inocente niña se metiera desnuda en la cama con ella. Quiero subrayar que, a pesar de que el deseo lesbiano se figura de modo monstruoso, y se dice soterradamente (invisibilizado por la postura doliente de la anciana), no deja de resultar revulsiva su aparición en un texto que trabaja con el imaginario de los cuentos de hadas, donde tradicionalmente sólo tenía lugar el deseo heterosexual.

"La verdad del bosque" comienza con una frase muy poética en la que algunos elementos de los cuentos de hadas aparecen estilizados casi al punto de dificultarse su reconocimiento: "Como un golfo de soles este espacio hermético y transparente: una esfera de cristal con el sol adentro; con un cuerpo dorado (un ausente, querido tú) con una cabeza donde brillan los ojos más azules delante del sol en la esfera transparente" (2014b, 34). El espacio hermético y transparente remite al ataúd de La bella durmiente. La esfera de cristal parece señalar ese clásico objeto mágico de la adivinación. Los ojos

\footnotetext{
5 Véase: Ludmila Barbero. 2018. "Belle comme un rêve de Pierre: La condesa sangrienta como reescritura de cuentos de hadas". Revista Anclajes 22 (1): 1-17. https://doi.org/10.19137/anclajes-20182211
} 
azules $^{6}$ podrían ser los de un príncipe o una princesa en un relato infantil. Pero la articulación de las entidades mentadas es propia de una poesía en prosa. A continuación: "La acción transcurre en el desierto y qué sola atravesé mi infancia como caperucita el bosque antes del encuentro feroz" (Ídem). En lugar de bosque tenemos un desierto. Pero el espacio que la protagonista atraviesa no es ese desierto sino su infancia. Las coordenadas espaciales y temporales están mezcladas. Los significantes que remiten a la soledad se superponen para hacer más desierto el desierto: "Qué sola llevando una cesta, qué inocente, qué decorosa y bien dispuesta" (Ídem). Hay un énfasis aquí en el aspecto de la pureza infantil que, de alguna manera, torna aún más contrastante la ferocidad del lobo. Pero también hay una tensión hacia lo sexual en los últimos dos adjetivos: "decorosa" y "dispuesta". Entonces, es posible ver aquí una deconstrucción de la idea de infancia como inocencia y pureza. Esa deconstrucción se ve enfatizada por el movimiento de suspensión de las certezas que tiene lugar en el segundo párrafo. Allí, la historia comienza a abrirse en un abanico metaficcional que la desarma, mostrando los procedimientos que la configuran. La devoración ocurre, pero no sólo incluye a las víctimas del cuento de hadas: "pero nos devoraron a todos porque ¿Para que sirven las palabras si no pueden constatar que nos devoraron? -dijo la abuela" (Ídem). Fuimos destruidos porque las palabras no sirven ni para dar cuenta de esa destrucción. La incapacidad del lenguaje para nombrar nos ha aniquilado más allá de las acciones del lobo. El bosque pierde su color, porque: "El bosque no es verde sino en el cerebro". Sin embargo, hay una insistencia en la representación minúscula de la escena primordial del cuento: "Pero allí, en mi pequeño teatro, el lobo las devoró. En cuanto al lobo, lo recorté y lo pegué en mi cuaderno escolar" (Ídem). El victimario aquí es una figurita de papel, a pesar de haberlas devorado. El develamiento del carácter literario/mental/pictórico de la secuencia central del relato desarma su materialidad, pero no su tragedia. Esta radica en la ausencia de una entidad objetivable: el lobo las devora, pero es una figurita recortable, el bosque es verde sólo en la mente. El no poder ubicar los objetos que se nombran más allá de su existencia mental es la forma en que el yo de este poema en prosa es tragado por la impotencia de las palabras. La anteúltima frase del cuento pone en evidencia el hecho de que la irrealidad del lobo no diluye el conflicto, sino que lo acrecienta. "En suma, en esta vida me deben el festín" (Ídem). El festín es a la vez la escena antropofágica en la que el lobo engulle a la abuela y a la niña, como así también, en términos más generales, los placeres de la vida, las gratificaciones. A esto, la abuela contesta, poniendo una vez más en entredicho el estatuto ontológico de todo aquello que el relato nombra: “- ¿Y a esto llamas vida?" (Ídem).

Entonces, en "La verdad del bosque" tiene lugar una escena que reescribe el cuento clásico Caperucita roja y, a su vez, una puesta en duda meta-literaria de los sucesos que en él se narran. El lenguaje no es fiable: “¿Para qué sirven las palabras?” (Ídem), el lobo no es 'real', sino una figurita recortable. El verde del bosque tiene sólo una existencia mental. Y, sin embargo, la escena "feroz" sigue teniendo fuertes resonancias para el 'yo' que narra la historia. Esto entra en sintonía con una constatación que se reitera en la escritura de Pizarnik: el hecho de que, aún si la tristeza es causada por la imaginación, el dolor es real. Recordemos a este respecto un fragmento de "A tiempo y no": "—-Todo es imaginación —replicó la muerte —en

\footnotetext{
${ }^{6}$ Los ojos azules también remiten al padre de Pizarnik. En "Poema para el padre" (1972) son los que le permiten al padre, en ausencia, cantar "la canción que quería cantar" (Pizarnik, 2014: 370). Son ojos que hablan más allá del acallamiento sufrido en vida, y de la muerte. Serán, a partir del 18 de enero de 1966, día de la muerte del padre, un elemento clave en las referencias de la poeta a él, en Diarios y Correspondencia.
} 
realidad no tiene la menor tristeza. -Pero sufre igual, entonces no hay ninguna diferencia — dijo la niña" (Pizarnik 2014b, 37). El socavamiento de las certezas en este relato es otro de los elementos que infectan la construcción de la infancia en Pizarnik: si en una construcción idílica de la niñez, la recordamos como el momento en el que las preguntas existenciales no nos asediaban, en su particular visión de este período los interrogantes "adultos" ya están ahí. Entonces, los eventos angustiantes que narra el cuento de hadas no se desvanecen al ponerse en duda su estatuto de realidad, porque las entidades mentales son aún más amenazadoras.

\section{Blancanieves}

"A tiempo y no", si bien no nos detendremos en este punto, reescribe "La historia de la tortuga de fantasía" de Alicia en el país de las maravillas, pero al mismo tiempo, el personaje de la Reina Loca guarda fuertes similitudes con la condesa Báthory ( $L a$ condesa sangrienta) y con la madrastra malvada de Blancanieves. ${ }^{7}$ Citemos el espacio mágico en que el relato ubica a la Reina: "A estas palabras el silencio se volvió a unificar y se hizo denso como una caverna o cualquier otro abrigo de piedra: dentro, entre las paredes milenarias, la joven reina rodeada de unicornios sonríe a su espejo mágico" (Pizarnik 2014b, 38). La reina de corazones no tenía un espejo mágico al cual sonreír. En A través del espejo y lo que Alicia encontró ahí (Carroll 1871), el espejo que la protagonista atraviesa es mágico, pero su carácter sobrenatural no se debe a su modo de reflejar, sino al jardín encantado donde puede conducir a quienes lo cruzan. El personaje de esta breve prosa pizarnikiana es una condensación de las dos reinas mencionadas.

De acuerdo con Bettelheim, "El tema central de Blancanieves es el de una niña que, todavía en la pubertad, supera, en todos los aspectos, a su perversa madrastra, quien, loca de celos, le niega una existencia independiente, simbólicamente representada por el esfuerzo de la madrastra por ver aniquilada a Blancanieves" (2013, 22). Blancanieves tiene un antecedente italiano, en el relato de Giambattista Basile, La joven esclava, ${ }^{8}$ recogido en Pentamerón. La versión de los hermanos Grimm, no obstante, es la más famosa, junto a la reversión cinematográfica de Walt Disney. Una escena de ese cuento, en particular, aparece reescrita en la prosa de Pizarnik. Cuando la madrastra malvada manda al cazador a matar a Blancanieves en el bosque, y le pide que le traiga los pulmones y el hígado de la niña para comerlos, él la engaña llevándole los órganos interiores de un jabalí. En el relato leemos: "Lleva a la niña al bosque. No quiero tener que volver a verla nunca más. Debes matarla y traerme sus pulmones y su hígado como prueba de tu acción" (Tatar 1999, 84). En la voz de la Reina Loca de

\footnotetext{
${ }^{7}$ También, se podría agregar, con la ogresa de La bella durmiente. En el relato de Perrault hay un segundo momento de la trama en el que aparece en escena la madre del príncipe, una ogresa que se complace engullendo niños pequeños.

${ }^{8}$ En este cuento, una hermosa princesa queda embarazada por tragarse el pétalo de una flor. Las hadas cuidan de la niña a la que da a luz. Pero una de ellas, por motivos caprichosos, decide transmitir a la pequeña una maldición, que se cumplirá cuando pase a la pubertad: caerá muerta por el uso de un peine mágico. Cuando esto ocurre, la madre la coloca dentro de siete ataúdes de cristal en una sala resguardada y oculta del castillo. Cuando la reina está por morir, deja las llaves de esta habitación al cuidado de su hermano. En un momento este último va de cacería, y su esposa descubre a la bella yacente. Muerta de celos por la belleza de la joven, la arranca del ataúd, la lastima y el peine se sale de la cabeza, con lo que la mujer vuelve a la vida. La joven vive como esclava y es muy maltratada por su tía, hasta que gracias a una muñeca a la que le confiesa sus penurias y al azar de que su tío el rey estuviera escuchándola, es rescatada y se salva.
} 
Pizarnik: "Hijo mío, tráeme la preciosa sangre de tu hija, su cabeza y sus entrañas, sus fémures y sus brazos que te dije encerraras en la olla nueva y la taparas, enséñamelo, tengo deseos de mirar todo eso; hace tiempo te lo di, cuando ante mí gemiste, cuando ante mí estalló tu llanto" (Pizarnik 2014b, 38). Resulta inevitable observar la relación de esta prueba física que aparecía en Caperucita con la prosa de Pizarnik. Las dos grandes divergencias en esta reescritura son, por un lado, la amplitud de los órganos/partes del cuerpo solicitados, y por otra la razón alegada para este pedido: si en Blancanieves se mentaba una causa objetiva para esa crueldad, en la prosa de Pizarnik la razón señalada es el deseo de ver. El relato de Pizarnik, entonces, reescribe la escena más truculenta del cuento de hadas. De esta manera, saca a la luz algo que ya estaba en el cuento de hadas tradicional, magnificándolo.

Gilbert y Gubar (2000) acuñan la antinomia "ángel del hogar" versus "monstruo", para dar cuenta de la visión polarizada de las figuras femeninas que las autoras del siglo diecinueve recuperan de una tradición literaria forjada por autores varones, para exhibir, de diversas maneras, las grietas de este modelo. Ellas analizan en detalle a los personajes femeninos de Blancanieves. Señalan la ausencia de la figura del padre en la trama, pero afirman que su voz y su juicio están presentes en las palabras del espejo: es la mirada patriarcal sobre la belleza la que se inflige sobre la reina. El rey es la voz en el espejo. Es el que decide, en primer lugar, que su esposa es la más bella de todas. Luego, cuando su esposa deja de ser la muchachita dócil y sumisa que era al inicio, es también él quien decide que ya no es la más bella, y que hay otra más pura e inocente que debe tomar su lugar. De acuerdo con estas autoras, no es necesario que el padre aparezca en la historia porque su perspectiva ya ha sido asimilada. Se encuentra en el espejo, esto es, en la cabeza de la reina, y, desde allí, determina su autopercepción. A diferencia de Bettelheim, quien no discute la perversión de la madrastra de Blancanieves, para Gilbert y Gubar, la madrastra es una artista ${ }^{9}$, una mujer de incontables recursos, una maga; mientras que Blancanieves representa un ideal de inactividad, pureza y quietud que literalmente asesina el dinamismo de la madrastra. En este sentido, quiero subrayar que Pizarnik elige, en sus referencias intertextuales a este cuento de hadas, a la madrastra: no hay reescritura del personaje de Blancanieves. En todo caso, su belleza y su quietud aparecerán en la reina loca, pero no adornarán una figura femenina ubicada en el lugar de la pureza, la inocencia y la docilidad.

Gilbert y Gubar consideran a las dos mujeres de la historia como partes enfrentadas de una misma identidad. La manzana doble, con una parte roja y una blanca (como Blancanieves), solo una de las cuales está envenenada, pone en evidencia la duplicidad que siente hacia su hijastra y enemiga, que es también una parte de su propio yo. Pero su hijastra dormida es mucho más peligrosa que viva, porque así es como encarna paradigmáticamente los ideales de inmovilidad y sumisión femenina del patriarcado. Así es como enamora al príncipe. Estas teóricas consideran que no existe salida para las mujeres del cuento, en tanto hay dos modelos muy estrictos y diferenciados a los que acomodarse: la pasiva Blancanieves, condenada a escapar de un ataúd de cristal para entrar a otro aún peor, el de la sumisión doméstica y el encierro familiar; la bruja malvada, cuyo castigo también es un silenciamiento violento en el

\footnotetext{
${ }^{9}$ Es interesante y ha sido notado tanto por Bettelheim como por Gilbert y Gubar, aunque sacando diferentes implicaciones, que las artes que utiliza la madrastra para matar a Blancanieves provienen todas de la imaginería y la técnica de lo femenino. Para la malvada reina estas artes matan, mientras que para la niña son tentadoras, como vías para acercarse al ideal de belleza al que la sociedad patriarcal propende. Desde el punto de vista de la Reina loca, las artes femeninas convencionales matan. Pero desde el punto de vista de la princesa dócil y desinteresada, tales artes, incluso mientras matan, confieren la única forma de poder disponible para una mujer en una cultura patriarcal (Gilbert, Gubar; 2000: 295).
} 
baile sobre zapatos (otra prenda característica de la femineidad) calentados al rojo vivo. En muchos personajes de Pizarnik se produce un mecanismo de condensación que rompe la tradicional polarización de las imágenes femeninas de los cuentos: tal es el caso de la vieja con cara de lobo en "Violario", que es a la vez lobo y abuelita. La reina de "A tiempo y no" es monstruosa en su relato, pero no hace ningún daño, y toda su maldad parece constreñida al universo de la imaginación. Reúne, de este modo, a la Reina de corazones de Alicia en el país de las maravillas, quien sentenciaba a muerte a todo el mundo, pero sus castigos nunca se cumplían, y a la madrastra malvada de Blancanieves. Asimismo, lo que rompe la polarización es la inexistencia de la niña inocente en el relato. La prosa de Pizarnik revisa un cuento que, en términos de las tecnologías de la infancia, servía a la construcción de un ideal de niña enmarcado en la pasividad y la sumisión, enfocándose en el personaje de la perversa madrastra, que en el relato "original" era sumamente activa, vital y creativa. Y el énfasis en el componente ominoso, ya presente en el texto reescrito, forma parte de una configuración de la niñez que es correlativamente oscura y siniestra.

\section{Bellas durmientes}

La sonámbula, figura omnipresente en la poesía pizarnikiana, tiene resonancias de los cuentos de hadas, en especial de estas figuras que experimentan "comas" prolongados, como Blancanieves y la bella durmiente. La figura de la sonámbula es central en $L a$ condesa sangrienta, y forma parte de la anómala construcción de la agencia criminal del personaje. Se trata de una homicida que, gracias a los procedimientos narratológicos de la pieza, parece no estar participando de los asesinatos que comete. ${ }^{10}$ Dado su fuerte valor simbólico para pensar la construcción de ciertos estereotipos de lo femenino, interesa indagar qué implicaciones tiene la ubicuidad de las sonámbulas en los textos de Pizarnik.

En un poema escrito entre 1956 y 1958, publicado bajo el título de "Aproximaciones", hay una suerte de reescritura de La bella durmiente del bosque:

como la bella en el bosque despierta para siempre sin príncipe que esperar

y la sonrisa muda se borró hace mucho

a dónde vas bajo el cielo gris oculto por pequeñas ventanas con ojos sucios donde detrás no hay nada nadie hay detrás y están todos muertos

la voz decía sobre el despertar y sobre la muerte y la voz decía y los ojos decían y todo estaba condenado pero la voz no se cansaba

ciudad de nada en nadie el cuerpo se hace la voz se rehace

\footnotetext{
${ }^{10}$ Véase para este punto: Ludmila Barbero, op. Cit.
} 
Esta bella durmiente tiene un destino diferente de aquella del cuento, porque ha pasado ya mucho tiempo y no hay ningún príncipe que la esté esperando ni a quién esperar. Todos han muerto salvo ella. Pero lo que pervive es una voz que insiste sobre el despertar y habla de la muerte. Una mujer en un espacio totalmente deshabitado, excepto por voces que la atormentan.

Las versiones más difundidas de La bella durmiente son, en orden cronológico, Sol, Luna y Talía, de Giambattista Basile (Pentamerón, 1634), La bella del bosque durmiente, de Charles Perrault (1697), y Rosita de Espino o La bella durmiente del bosque, de los hermanos Jacob y Wilhelm Grimm (1812). Las más famosas son las dos últimas. Es central, en ambas, la idea de la juventud eterna (la belleza y lozanía de la princesa se mantienen incólumes durante cien años de sueño gracias al hechizo del hada buena), y el tema del letargo-inconsciencia-ausencia del propio cuerpo, tópicos recurrentes, además, en una serie de cuentos de hadas. Bettelheim entiende el sueño como momento de maduración interna y silenciosa: "El mensaje es paralelo al de Blancanieves: lo que puede parecer un período de pasividad total al finalizar la infancia, no es más que un lapsus de crecimiento reposado y preparación, del que la persona despertará más madura y dispuesta ya para la unión sexual" $(1994,254)$. Pero resulta sugerente que en los cuentos de hadas que han pasado a la posteridad, los personajes que sufren estos letargos prolongados en los que, de acuerdo con Bettelheim, habría una maduración interna (presuntamente, porque nada indica que las protagonistas maduren en el sueño), sean siempre mujeres. Llama la atención que estas mujeres conquisten a los príncipes desde la más absoluta pasividad: para enamorar hay que ser bellas, mudas y quietas, como un sueño de piedra. "Aproximaciones" es una versión pesadillesca de La bella durmiente del bosque: la bella despierta y todas las personas que debían acompañarla han muerto. El príncipe nunca llega. La atmósfera que rodea el despertar es oscura y opresiva. No hay esperanza para las lánguidas princesas de los cuentos, parece decirnos este poema.

La imagen de la mujer dormida, y de la sonámbula son abundantes en la escritura pizarnikiana, tanto en su prosa como en su poesía. En el poema 32 de Árbol de Diana (1962), hay elementos que remiten tanto a La bella durmiente como a Blancanieves: "Zona de plagas donde la dormida come / lentamente / su corazón de medianoche" (2014a, 134). Comerse el corazón recuerda al método de comprobación de la madrastra malvada en Blancanieves, y dormidas están las protagonistas tanto de esa historia como la de la bella que habita el palacio adormecido. El poema anterior, leído en sucesión con este, también tiene fuertes resonancias de La bella durmiente: "Es un cerrar los ojos y jurar no abrirlos. En tanto afuera se alimenten de relojes y de flores nacidas de la astucia. Pero con los ojos cerrados y un sufrimiento en verdad demasiado grande pulsamos los espejos hasta que las palabras olvidadas suenan mágicamente" (133). Hay un interior en el que alguien cierra los ojos, y un exterior en el que el tiempo pasa, tal como en el cuento. Espejos, un olvido de las palabras, y una suerte de magia. El trastocamiento de los elementos genera una poesía que habla de otra cosa: de una subjetividad reconcentrada, situada en un más allá del Cronos, en un detenimiento mágico. En la poesía 36 del mismo poemario se produce un movimiento en la contemplación de la belleza dormida: no hay un sujeto masculino cuya mirada deseante recaiga sobre el cuerpo dormido de una mujer. Es la misma mujer dormida la que se mira: "en la jaula del tiempo / la dormida mira sus ojos solos / el viento le trae / la tenue respuesta de las hojas" (138).

En el poema IX de Los pequeños cantos (1971), se lee: "mi canto de dormida al alba" (2014a, 387). En “Aproximaciones”, además de la versión de La bella durmiente 
que ya mencioné, se lee "Una flor en mi mano de sonámbula" (313). También en el poema 17 de Árbol de Diana hay muchos elementos que configuran la imagen de una dormida, sonámbula, muerta, autómata:

\begin{abstract}
Días en los que una palabra lejana se apodera de mí. Voy por esos días sonámbula y transparente. La hermosa autómata se canta, se encanta, se cuenta casos y cosas: nido de hilos rígidos donde me danzo y me lloro en mis numerosos funerales. (Ella es su espejo incendiado, su espera en hogueras frías, su elemento místico, su fornicación de nombres creciendo solos en la noche pálida).
\end{abstract}

Este poema podría pensarse como un pequeño teatro de marionetas del 'yo' construido a partir de un prolijo desmembramiento y recomposición de los elementos del cuento de hadas.

No es difícil conectar a las muñecas, también omnipresentes en la escritura pizarnikiana, con la idea de la docilidad/pasividad femenina que se revela en esta construcción de la belleza de las mujeres dormidas. En este sentido, la condesa sangrienta, que aúna los rasgos de la muñeca y la autómata con los de la mujer dormida, es descripta en diversos momentos de las dos maneras: es "la sonámbula vestida de blanco" (2014a, 284), y es configurada en cercanía con su autómata predilecta, la virgen de hierro. Si pensamos los cuentos de hadas, no sólo como "tecnologías del género" sino también como "tecnologías de la infancia", es posible ver cómo se atribuye a la niña una docilidad y una pureza que reaparecen en las versiones de Pizarnik, pero con un halo monstruoso. Quiero decir, no es lo mismo ser una niña sensata que espera, que ser una autómata y una sonámbula. En la caracterización pizarnikiana se pone en evidencia la anomalía de las construcciones de la niñez femenina que aparecen en los cuentos de hadas.

En las reescrituras que he analizado llaman la atención en particular algunos corrimientos respecto de los cuentos de hadas tradicionales retomados. En primer lugar, en "Violario" hay señales de un clóset del deseo lesbiano, en la medida en que este deseo se construye a través de un personaje monstruoso y sin exhibirlo a plena luz: la vetusta femme de lettres no parece estar haciendo otra cosa sobre el cuerpo de la adolescente que acompañarlo en un momento de dolor; si bien no nos detuvimos aquí en La condesa sangrienta, de Báthory se dirá que su homosexualidad no está comprobada, sino que se trata apenas de un rumor. No obstante, a pesar de estar construido desde el clóset, el deseo lésbico aparece. Por otro lado, en textos como "La verdad del bosque" y "Aproximaciones", la principal tragedia tiene que ver con el lenguaje, la soledad y la infinita especularidad del yo. Además, la amalgama entre los personajes que en los cuentos de hadas cumplían los roles de ángel del hogar y mujermonstruo da cuenta de un corrimiento respecto de la visión antinómica de lo femenino a que hacen referencia Gilbert y Gubar. La centralidad de las figuras femeninas en las reescrituras pizarnikianas también puede ser leída en clave crítica: allí donde en los cuentos de hadas tradicionales los detentores de mayor poder en las tramas narrativas eran hombres, Pizarnik construye gineceos.

\title{
La que espera
}

Una de las posiciones características de la mujer, de acuerdo con Simone de Beauvoir, que resulta típica de los cuentos de hadas, es la paciente espera del amor. En sus palabras: "Aprende que, para ser dichosa, hay que ser amada, y, para ser amada, hay 
que esperar el amor. La mujer es la Bella Durmiente del Bosque, Piel de Asno ${ }^{11}$, Cenicienta, Blanca Nieves, la que recibe y sufre" (Beauvoir 2017, 230). El amor y la magia están asociados en los cuentos de hadas: son los Deus ex machina que movilizan la resolución de las tramas narrativas. Lo que saca a la joven del conflicto en que se encuentra es el amor, vehiculizado por una resolución en la que la magia es central: si se piensa en Cenicienta, su posición es la de una espera pasiva, de la que es arrancada a través de un hada madrina, que con magia resuelve toda su situación. La bella durmiente recibe una reducción del maleficio a través de un hada buena (magia), y es arrancada del sueño gracias a una mezcla de amor y azar (el azar también es mágico en los cuentos de hadas). Blancanieves, que tiene en su contra magias muy oscuras, puede escapar a los maleficios de la madrastra malvada gracias al amor y al azar (una vez más). En Pizarnik abundan las imágenes de figuras femeninas en actitud de espera. Relevaré algunas provenientes de su poesía:

De Un signo en tu sombra, en "Irme en un barco negro": "mi pluma retarda el TÚ anhelante / mi sien late mil veces TU nombre / si tus ojos pudieran venir" (Pizarnik 2014a: 37). En el poema "La enamorada", de La última inocencia, hay una pequeña instantánea o viñeta de cuento de hadas fallido: "hoy te miraste en el espejo / y te fuiste triste estabas sola / la luz rugía el aire cantaba / pero tu amado no volvió" (Ídem, 53). En "La luz caída de la noche", de Las aventuras perdidas: "vierte esfinge / tu llanto en mi delirio / crece con flores en mi espera" (Ídem, 89). Mucho después, en Extracción de la piedra de locura: "Si no vino es porque no vino. Es como hacer el otoño. Nada esperabas de su venida. Todo lo esperabas" (Ídem, 251).

Interesa pensar si en la obra de Pizarnik la recurrencia de la figura de la mujer que espera dice algo más que lo que implicaría la adopción de una figuración de género opresiva. Cabe preguntarse por el valor de subrayado que tiene la reiteración del topos. La proliferación de esta imaginería de las mujeres en actitud expectante marca una zona conflictiva en las representaciones tradicionales de lo femenino.

\section{La sirenita}

La figura de la sirena aparece en el poema "La enamorada", que ya mencioné en relación con el lugar de espera:

La enamorada

esta lúgubre manía de vivir esta recóndita humorada de vivir te arrastra Alejandra no lo niegues.

hoy te miraste en el espejo $\mathrm{y}$ te fue triste estabas sola la luz rugía el aire cantaba pero tu amado no volvió

enviarás mensajes sonreirás tremolarás tus manos así volverá tu amado tan amado

\footnotetext{
${ }^{11}$ La única heroína, de las mencionadas por de Beauvoir, que no es paciente y pasiva es Piel de asno. Ella entra en la saga de las aventureras con recursos y capacidades intelectuales, que logran sobrevivir a las malas intenciones de los hombres.
} 


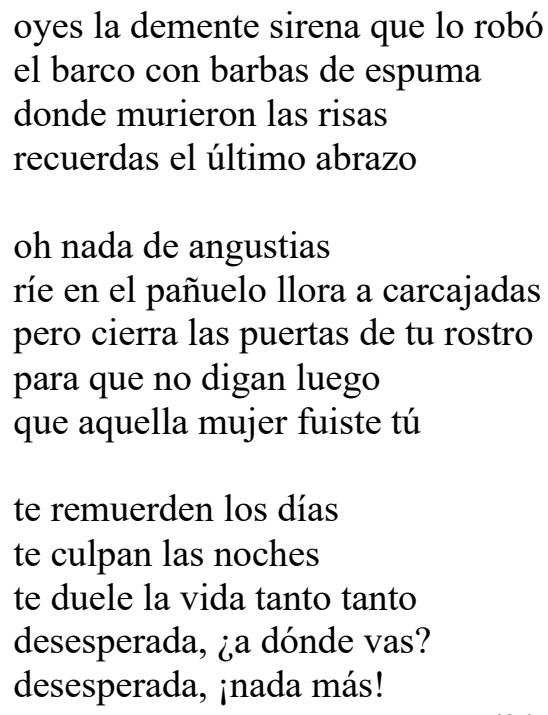

(2014a: 53)

Si bien la sirena es una figura legendaria autónoma, también forma parte de uno de los cuentos de hadas tradicionales más famosos de la cultura occidental: La sirenita (1837), de Hans Christian Andersen, historia que luego Disney se ocupó de atemperar y de darle un final feliz. La caracterización de la protagonista en el relato, al tiempo que hermosa y extremadamente pálida, es "tranquila y pensativa" (Andersen 2010, 558), y en sintonía con la postura de paciente espera, debe dejar pasar mucho tiempo hasta que sus padres la autorizan, como a sus hermanas mayores, a salir a la superficie del mar para ver qué hay más allá. La sirenita es curiosa, tiene iniciativa y, a fin de cuentas, termina violando las leyes de su propia especie movida por su deseo, cuando le pide a la bruja del mar que transforme su cola en un par de piernas para poder acercarse al príncipe de quien se había enamorado. Pero su voluntad está fuertemente asociada al mandato matrimonial: la bruja le explica que, una vez convertida en humana, para conseguir un alma inmortal debe casarse con el príncipe, y este debe amarla más que a sus propios padres. Ella sacrifica su vida submarina, su longevidad, a su familia, su reino, su bienestar corporal (cada paso que da se siente como ser atravesada por afilados cuchillos), y su voz (es la prenda solicitada por la bruja a cambio de las piernas), por poder estar cerca del príncipe como humana.

Laura Arnés (2016) asocia la figura de la sirena y su desarrollo en la literatura argentina, desde La sirena (1903) de Octavio Bunge en adelante, a la figura de la lesbiana. Salirse del género y de la sexualidad normativa implica ubicarse por fuera de la especie, entrar al terreno de la teratología (lo monstruoso acecha toda tentativa de fuga de la normatividad). Sobre el monstruo pesa la amenaza de esterilidad: constituye una especie en sí misma, y este carácter ajeno a la reproducción sexual también está en la lesbiana. Con esta idea en mente, no resulta extraño que la figura sea recuperada en el poema de Pizarnik. Llama la atención que justamente la sirena cifre un modo de configurar a la lesbiana en la literatura argentina, si se considera que es un ser mitológico que no tiene genitalidad: este elemento explica el origen masculino de la ficción. Desde una mirada heteronormativa, masculina, patriarcal, la sexualidad lesbiana no es concebida como una práctica sexual plena. Si salirse de la heteronorma es salirse de la especie (Arnés, Giorgi), en el cuento de Andersen, la protagonista busca literalmente una existencia fuera de su especie movida por el deseo amoroso.

La sirena del poema de Pizarnik está loca, y, en un juego especular muy típico de la autora, puede ser ella misma: "para que no digan luego que aquella mujer fuiste 
tú” (2014a, 53). El motivo mitológico aparece en esta poesía para aportar otro matiz a los conflictos subjetivos de la soledad, el desdoblamiento, la locura, ubicándolos en la clave de la amada abandonada, que espera. Pero no se trata de una espera paciente como en la versión de Andersen, sino de una mujer "desesperada", que exhibe su pathos, sin ningún refrenamiento. El personaje de Andersen, como todas sus heroínas, toma su destino con estoicismo, pero la figura construida por Pizarnik, asociada especularmente a la sirena, vive su lamento con intensidad. Aquí se torsiona esta imagen mítica: al exponer la tragedia oponiéndose a la tradición de la conformidad/pasividad de las mujeres a la espera. La sirenita es, dentro de los relatos de Andersen, el personaje que con mayor virtuosismo soporta en silencio el dolor. "Of all Andersen's characters, it is probably the little mermaid who is the real virtuoso in the art of silent suffering. With her tongue cut out by the sea witch, she drinks a potion designed to endow her with legs and feels a 'two-edged sword' piercing her 'delicate body"'12 (Tatar 1999, 214).

La figura de la sirena vuelve a aparecer en dos ensayos de Pizarnik, ${ }^{13}$ y en los Diarios, aunque en estos últimos su presencia no resulta significativa ${ }^{14}$, Me detendré en "Una tradición de la ruptura", donde Pizarnik analiza Cuadrivio, ensayo de Octavio Paz sobre cuatro poetas, entre los que se cuenta Ruben Darío. Analiza aquí la perspectiva de este último poeta, que resulta polarizadora sobre las mujeres, y su representación de la muerte como mujer:

Al mismo tiempo, es significativo que Darío denomine a la muerte Ella y que su actitud ante Ella sea ambigua y perfectamente erótica: le produce un terror absoluto y, a la vez, la espera como a una amante. Por una parte, la muerte es lo extraño que acecha desde lo oculto, y por la otra, es un objeto de deseo, capaz de proporcionar delicias desconocidas e intensísimas. La muerte fue su medusa y su sirena. Muerte dual, como todo lo que tocó, vio y cantó. La unidad es siempre dos.

(2014b, 236-237)

Aunque Pizarnik no emplee este término, reconoce que se trata de una mirada binaria sobre lo femenino, que lo encasilla en posiciones irreconciliables $\mathrm{y}$, de este modo, torna a las mujeres inhumanas, inaccesibles e irreales. Ellas no tienen matices en la tradición modernista, deben ajustarse a un molde que las constriñe: ser o bien inocentes y encantadoras o monstruos demoníacos. No hay espesor psicológico ni conciliación de la diversidad. Pero la figura de la sirena en el poema "La enamorada" no involucra una visión polarizada de lo femenino, porque el yo poético se habla a sí mismo cuando relata la desesperación del 'tú', y se identifica también con la "demente sirena": no hay lugar para la paciente pasividad aquí.

\footnotetext{
12 "De todos los personajes de Andersen, la sirenita es la verdadera 'virtuosa' en el arte de sufrir en silencio. Con su lengua cortada por la bruja del mar, ella bebe una poción destinada a proporcionarle piernas, y siente una 'espada de doble filo' atravesando su 'delicado cuerpo"” (Traducción propia).

${ }^{13}$ En un ensayo de Pizarnik, titulado "Passages de Michaux", las sirenas aparecen mencionadas como uno de los temas de su libro, como parte de un listado tan heteróclito que la hace pensar en un poema surrealista.

${ }^{14}$ En los Diarios, también hay sirenas. En una entrada del 23 de octubre de 1957, las encontramos en una referencia a la poesía de John Donne, cuyos versos cita y se ocupa de criticar por la sucesión de lirismo y prosaísmo que encarnan, sin solución de continuidad: "Enséñame a oír el canto de las sirenas, / o a guardarme del aguijón de la envidia" $(2013,195)$.
} 


\section{Hansel y Gretel}

Según Bettelheim, Hansel y Gretel (Grimm 1812) aborda la superación de las pulsiones orales por parte de los niños, en función de formas de comportamiento socialmente más equilibradas. De acuerdo con María Tatar, no obstante, el tema principal del relato es el abandono de los padres. Coincido con ella en que el conflicto central no es la glotonería sino el abandono y la orfandad. En ese sentido se entiende que a lo largo de la obra pizarnikiana este relato sea el más aludido, si bien no es reescrito por completo. Se trata de menciones desperdigadas a lo largo de toda su obra. La desolación de esos niños lanzados a la intemperie por sus propios padres halla un fuerte eco en el vacío metafísico que la pluma de Pizarnik procura saldar. De todas maneras, el componente oral (la privación de alimentos) de la tragedia de los niños perdidos en el bosque no deja de resultar significativo, si se tiene en cuenta que uno de los grandes dramas de Pizarnik con su corporalidad tiene que ver con negarse, voluntariamente, la comida. Quisiera que veamos cómo aparecen Hansel y Gretel en la obra de Pizarnik. En "Extracción de la piedra de locura" (1964):

De repente poseída por un funesto presentimiento de un viento negro que impide respirar, busqué el recuerdo de alguna alegría que me sirviera de escudo o de arma de defensa, o aún de ataque. Parecía el Eclesiastés: busqué en todas mis memorias y nada, nada debajo de la aurora de dedos negros. Mi oficio (también en el sueño lo ejerzo) es conjurar y exorcizar. ¿A qué hora empezó la desgracia? No quiero saber. No quiero más que un silencio para mí y las que fui, un silencio como la pequeña choza que encuentran en el bosque los niños perdidos. ${ }^{15} \mathrm{Y}$ no sé yo qué ha de ser de mí si nada rima con nada.

(2014a, 248)

Como señala Alicia Genovese en Leer poesía, la poesía recupera el silencio, y da lugar a "un vacío creado para encontrar el propio ritmo, la propia sintaxis, la puntuación dentro de la cual respirar y el tono, esa cámara de resonancia de la subjetividad" (2011, 17). Este vacío en el que resuena la propia respiración es ese espacio habitable que encuentran los niños extraviados en el bosque, es el lugar donde se cifra una escapatoria a la intemperie, a la orfandad.

En "Relectura de Nadja, de André Breton" hay muchas referencias a cuentos de hadas. Entre ellas:

Sombras talladas por un relámpago negro, estas bellas extraviadas no hallan en la noche la casita de Hansel y Gretel, sino a otra viajera más sombría y dotada del poder de ocultar. Con ella se abrazan y en ella desaparecen como quien entra en una gruta encantada (...tu no tendrás en esta vida otros placeres que aquellos que se prometen los niños mediante la idea de grutas encantadas y fuentes profundas).

(2014b, 263)

La metáfora del refugio que encuentra una mujer "extraviada" sigue siendo la casita del bosque de Hansel y Gretel: esta es siempre la imagen paradigmática del refugio, porque la infancia no deja de ser el lugar al que Pizarnik se imagina volver.

En una entrada de sus Diarios, del 6 de marzo de 1964:

\footnotetext{
${ }^{15}$ Las cursivas son nuestras. 
El cielo arriba y las aguas abajo y yo a los gritos delante de la guitarra de Bob. Ondas de lenguaje subían a mis labios como si hablara una estatua. Arquitectura de mi espíritu: la casa de Hansel y Gretel después de un incendio. Fue allí cuando supe que algo en mí estaba roto, que me habían arruinado. Que me habían empotrado en el sitial mayor del reino de la separación.

$(2013,665)$

La máxima desolación es la casa de Hansel y Gretel incendiada: la ruina que cae sobre ese último refugio. El espíritu tiene una arquitectura, y esto tiene mucho que ver con el modo en que Pizarnik piensa lo psíquico con metáforas espaciales. Los hermanos del cuento, en su vagar, en su estar arrojados a un mundo del que nada saben, en la orfandad con que atraviesan el bosque, metaforizan un estado de absoluto abandono. La casita funciona como una suerte de último asilo para cobijarse de la intemperie. Pero este refugio está permanentemente amenazado. En una entrada de sus Diarios, del $1^{\circ}$ de junio de 1965, se lee:

O si se cierran, entonces sucede algo con las hendiduras, pues el aire no pasa y los moradores de la casita del bosque perecen asfixiados. No, nadie perece pues no se pueden cerrar. Más bien están heridos, heridos, pero no muertos, aunque bien quisieran estar muertos, están heridos por el viento filoso.

$(2013,720)$

Luego, el 16 de diciembre de 1968, señala:

Además, me obligan a escribir en un estilo filoso y a cuidar que no sobre ningún término, con lo cual mi abandono del poema pierde sentido, puesto que mis cambios de formas, que yo llamaría cambios espaciales, tienen por objeto hallar un espacio literario como una patria o, si esto es demasiado, como la choza que encuentran en el bosque los niños perdidos.

$(2013,841)$

Entonces, ahora ya no es el espíritu metaforizado con la imagen de la pequeña choza, sino el estilo, su estilo. Hansel y Gretel aporta, a través de la choza que encuentran los niños perdidos en su vagar por el bosque, una imagen cara a Pizarnik, que será retomada como refugio ante la desolación y el abandono, pero un refugio que no se muestra del todo seguro. Pensemos, en ese sentido que, en el cuento de hadas, esa casita resulta ser más prisión que refugio (es solo en apariencia refugio).

A través de las diversas reescrituras de cuentos de hadas que Pizarnik realiza tanto en sus prosas como en sus poemas e incluso en sus Diarios, tienen lugar diferentes apropiaciones. "Violario" construye una narrativa en la que el deseo lésbico es ubicado en el centro de Caperucita roja. En "La verdad del bosque" a través de un movimiento metaficcional se cuestiona el estatuto de verdad de lo narrado, poniendo en entredicho los saberes que comunica el cuento de hadas. "Aproximaciones" es una versión pesadillesca de La bella del bosque durmiente en la que se nos dice que las promesas de los cuentos de hadas no se van a cumplir. "A tiempo y no" configura un personaje femenino monstruoso en el que se tocan elementos característicos del "ángel del hogar" y el monstruo. Las durmientes, las sonámbulas y las mujeres que esperan en la obra de Pizarnik aparecen obsesivamente, y sus desvelos no resultan recompensados. Su sirena y su enamorada en "La enamorada" no sufren en silencio, sino que exhiben su desesperación. Si la construcción de lo femenino se halla fuertemente vinculada con la construcción de la niñez, en tanto las mujeres hemos sido, a menudo, ubicadas en una posición de minoridad con respecto a la autoridad y poder masculinos, analizar las 
reescrituras pizarnikianas de cuentos de hadas posibilita indagar las torsiones que tienen lugar en relación con esta configuración que subalterniza lo femenino. La imagen de la infancia que configuran estas reescrituras presenta elementos que remiten a la sexualidad, a la violencia, y a la muerte, pero no plantean una solución compensatoria en la que la angustia (del niño) pueda resolverse, función que, de acuerdo con Bettelheim, tienen los cuentos de hadas. Más bien tensan esa angustia, y ponen en evidencia tanto los aspectos ominosos de los cuentos de hadas tradicionales, como las grietas en la construcción de infancia a que estos daban lugar.

\section{Bibliografía}

Andersen, Hans Christian. 1999 [1837]. "The Little Mermaid". The Classic Fairy Tales, coordinado por Maria Tatar, 216-234. New York: Norton and Company.

Arnés, Laura. 2016. Ficciones lesbianas. Literatura y afectos en la cultura argentina. Buenos Aires: Madreselva.

Barbero, Ludmila. 2018. "Belle comme un rêve de Pierre: La Condesa Sangrienta de Alejandra Pizarnik como reescritura de cuentos de hadas." Revista Anclajes 22 (1): $1-17$. https://cerac.unlpam.edu.ar/index.php/anclajes/article/view/1333/2067

Barnes, Djuna. 1936. Nightwood. Londres: Faber and Faber.

Basile, Giambattista. 1999 [1634]. "The Young Slave" (Pentamerone). The Classic Fairy Tales, coordinado por Maria Tatar, 80-83. New York: Norton and Company.

Beauvoir, Simone de. 2017 [1949]. El segundo sexo. Buenos Aires: De Bolsillo.

Bettelheim, Bruno. 1994 [1976]. Psicoanálisis de los cuentos de hadas. Barcelona: Crítica.

Brownmiller, Susan. 1976. Against our Will. Man, Women and Rape. New York: Fawcett Columbine.

Copello, Fernando, Marina Letourneur y Lucie Valverde, comps. 2020. 3 poetas 3. Ensayos sobre la infancia en la obra de Juan Gelman, Alejandra Pizarnik y María Elena Walsh. Ciudad Autónoma de Buenos Aires: Dedalus/Le Mans Université.

Genovese, Alicia. 2011. Leer poesía: Lo leve, lo grave, lo opaco. Buenos Aires: FCE.

Gilbert, Sandra and Susan Gubar. 2000 [1979]. The Madwoman in the Attic: The Woman Writer and the Nineteenth-Century Literary Imagination. New Haven: Yale University Press. 
Grimm, Wilhelm Karl \& Jacob Ludwig. 1999 [1812]. "Little Red Cap"; "Hansel and Gretel". The Classic Fairy Tales, coordinado por Maria Tatar, 13-16 y 184-190. New York: Norton and Company.

Mackintosh, Fiona. 2003. Childhood in the Works of Silvina Ocampo and Alejandra Pizarnik. Woodbridge: Tamesis.

Perrault, Charles. 1999 [1697]. "Little Red Riding Hood”. The Classic Fairy Tales, coordinado por Maria Tatar, 11-13. New York: Norton and Company.

— 1980 [1697]. "Le chaperon rouge”. Les contes de Perrault. París: Sacelp. 1114.

Pizarnik, Alejandra. 2014a. Poesía completa. Buenos Aires: Lumen.

- 2014b. Prosa completa. Buenos Aires: Lumen.

—. 2013. Diarios. Barcelona: Lumen [ed. Ana Becciú].

Punte, María José. 2018. Topografias del estallido: figuras de infancia en la literatura argentina. Buenos Aires: Corregidor.

Stockton, Kathryn. 2009. The queer child. Londres: Duke University Press.

Zohar Shavit. 1999 [1983]. “The Concept of Childhood and Children's Folktales: Test Case - 'Little Red Riding Hood"'. The Classic Fairy Tales coordinado por Maria Tatar, 317-332. New York: Norton and Company. 